\title{
Retomando a educação ambiental crítica a partir dos pressupostos de Paulo Freire e Enrique Dussel
}

André Luis Castro de Freitas ${ }^{1}$

Luciane Albernaz de Araujo Freitas²

\section{Resumo}

O estudo tem como objetivo constituir aproximações entre o campo da educação ambiental crítica e os pressupostos trabalhados por Freire e Dussel. A partir de um estudo descritivo crítico, resultante de uma pesquisa de abordagem qualitativa, bibliográfica, tem-se como intenção elencar a relevância no campo das relações educativas as categorias: alteridade, diálogo e dialética. Reflete-se sobre a dicotomia existente entre uma educação ambiental a qual anuncia boas práticas individuais e aquela a qual denuncia a insustentabilidade. Na segunda parte, compreende-se sobre a necessidade de que se caminhe na direção da liberdade do Outro para que se alcance a própria. Após, encaminha-se uma discussão a qual trata o respeito à vida, pela valorização da identidade cultural dos seres humanos.

Palavras-chave: Alteridade; Diálogo; Dialética.

\section{Revitalizing critical environmental education from the foundations of Paulo Freire and Enrique Dussel}

\section{Abstract:}

The study aims to build approximations between the field of critical environmental education and the foundations studied by Freire e Dussel. Based on a critical descriptive study, resulting from a qualitative and bibliographical research, it is intended to enumerate the relevance in the field of educational relations the categories: alterity, dialogue and dialectics. It reflects on the dichotomy between an environmental education which announces good individual practices and another that denounces unsustainability. In the second part, one understands about the necessity of that one moves in the direction of the freedom of the Other so that it arrives at own. Afterwards, a study is made which deals with respect for life, for the valorization of the cultural identity of human beings. Keywords: Alterity; Dialogue; Dialectics.

\section{Considerações Iniciais}

O enfrentamento dos problemas socioambientais pelos quais passa a sociedade contemporânea, não se limita a questões referentes, exclusivamente, ao meio-ambiente, tal que não se trata de uma dificuldade de caráter cultural ou comportamental, mas de uma crise no modelo civilizatório, associada essa à lógica de produção capitalista.

Nessas condições, a expansão da produção capitalista está atrelada a um crescimento

\footnotetext{
${ }^{1}$ Universidade Federal do Rio Grande (FURG), Rio Grande-RS, e-mail: dmtalcf@furg.br.

${ }^{2}$ Instituto Federal Sul Rio-Grandense (IFSUL), Pelotas - RS, e-mail: lucianel1968@gmail.com.
} 
econômico ilimitado o qual exerce pressão sobre a utilização dos recursos naturais e sobre a capacidade de suporte a vida no mundo.

Refletir na superação da crise socioambiental é promover o pensar para além de mudanças de caráter apenas conjuntural, pois essas não abalam os mecanismos de reprodução social mantendo inalteradas as relações de poder. Principiando por essa premissa, acredita-se que o papel da educação ambiental crítica, a qual deverá partir de uma situação concreta, ou seja, o esgotamento das condições materiais do planeta e suas decorrências, tendo como base ontológica e gnosiológica, o materialismo histórico e dialético, é propor o entendimento da “[...] educação não como o único meio para a transformação, mas como um dos meios sem o qual não há mudança" (LOUREIRO, 2006, p.58). Compreender a educação ambiental crítica em sua amplitude e complexidade permite fazer de seus pressupostos balizadores a construção de uma educação e, sobretudo, de uma prática pedagógica que esteja em sintonia com os anseios de contribuir com o processo contra-hegemônico.

Por outro lado, Layrargues (2018) afirma que na contemporaneidade a educação ambiental foi atravessada pelo signo do antiecologismo ${ }^{3}$ em que foi consolidado um conservadorismo pedagógico, tornando essa educação hegemonicamente reprodutivista, implicada, de maneira generalizada, como os valores de sociabilidade do capital, omitindo, por sua vez, o quadro histórico-crítico que contribui para os esclarecimentos sobre as contradições da sociedade capitalista.

Assim, a educação ambiental foi modificada para contribuir com o processo de estabelecimento de um padrão normal a ser cumprido, em favor de uma identidade pacificada e controlada, um modo de comportamento ecologista desejável, moderado, desqualificando, ao final, o pensamento crítico.

Os problemas dissertados até aqui representam o que se poderia chamar de situações-limites ${ }^{4}$ da dimensão socioambiental, momento em que há a necessidade de

\footnotetext{
${ }^{3}$ Para Layrargues (2018), o antiecologismo representa o retorno da prevalência econômica, em nome de um ajuste com vistas a reequilibrar a relação entre economia e ecologia. Para o autor, "[...] a narrativa de sustentação do antiecologismo se baseia nos excessos cometidos na era ambiental pelo ecologismo ter sido excessivamente rigoroso com a criação de todo um aparato político-institucional de proteção ambiental, que não mais deveria inviabilizar o crescimento econômico" (p.33).

${ }^{4}$ Para Freire (2004) as situações-limites se apresentam como determinantes históricas, provocando aos seres humanos uma adaptação à realidade em que se encontram. Para o autor, no momento em que, na ação, se instaura a percepção
} 
questionar: Em que medida é possível a criação de novos encaminhamentos para os seres humanos ${ }^{5}$, no que implique as relações desses no e com o mundo? Deve-se levar em consideração que a educação ambiental passa por um momento em que se faz presente a dicotomia entre a ação de preservar, inserida em uma educação que anuncia boas práticas individuais, e a ação de transformar a realidade, presente em uma educação que denuncia a insustentabilidade.

Nesse contexto, aproximam-se as relações educativas propostas por Paulo Freire e Enrique Dussel, autores esses que partem do princípio de que a educação é um caminho para que os seres humanos formem uma consciência crítica diante dos problemas da realidade e possam agir no sentido de transformá-la. Nesse caso, o papel do educador é promover a apreensão da realidade em partilha com os educandos, estando aberto a um, permanente, aprender e ensinar.

Com o foco no campo da educação ambiental, a intencionalidade do texto aqui proposto, fundamentado a partir de uma pesquisa qualitativa, de base bibliográfica, é problematizar a partir dos pressupostos de Paulo Freire e Enrique Dussel as categorias alteridade, diálogo e dialética, no que implique mediar e gerar ações transformadoras no e com o mundo, refletindo sobre as práticas dessas ações. O texto está descrito da seguinte forma: As desigualdades socioculturais e a educação ambiental - reflete-se, no que pese o contexto de uma educação ambiental, a dicotomia existente entre uma educação a qual anuncia boas práticas individuais e aquela a qual denuncia a insustentabilidade; Alteridade e diálogo compreende-se sobre a necessidade de que se caminhe na direção da liberdade do Outro para que se alcance a própria; e $O$ respeito à vida e o movimento dialético - estuda-se a relação entre objetividade e subjetividade como dialética, no sentido de constituir o pensar e o atuar na realidade para que se possa transformá-la, valorizando a identidade cultural dos seres humanos. Após seguem as considerações finais.

crítica irá "[...] se desenvolver um clima de esperança e confiança que leva os homens a se empenharem na superação das 'situações-limites'" (FREIRE, 2004, p.91, grifo do autor).

${ }^{5}$ Acompanhando as ideias freirianas, ao longo do texto será utilizado o termo ser humano como forma de abranger as questões de gênero. $\mathrm{O}$ termo homem foi utilizado por Freire no sentido genérico com o significado de homem e mulher, mas, a partir da obra Pedagogia da esperança: um reencontro com a pedagogia do oprimido, o autor fez a alusão, específica, ao gênero feminino. "Daquela data até hoje me refiro sempre a mulher e homem ou seres humanos. Prefiro, às vezes, enfeiar a frase explicitando, contudo, minha recusa à linguagem machista" (FREIRE, 2002, p.68). 


\section{As desigualdades socioculturais e a educação ambiental}

As desigualdades sociais oriundas do desenvolvimento do modelo civilizatório se alastram para a dimensão ambiental, estabelecendo, na visão de Layrargues (2006), materialidade a uma nova desigualdade. Segundo o autor, essa materialidade se expressa no conceito de vulnerabilidade ambiental que atinge grupos sociais em condições de vulnerabilidade social, econômica e política, tendo suas condições de vida ou de trabalho ameaçadas pela degradação ambiental, causada pela exploração dos recursos naturais de maneira indevida.

Para Herculano (2002), a existência crescente dessa desigualdade é chamada de injustiça ambiental, definida como o "[...] mecanismo pelo qual sociedades desiguais destinam a maior carga dos danos ambientais do desenvolvimento a grupos sociais de trabalhadores, população de baixa renda, grupos raciais discriminados, populações marginalizadas e mais vulneráveis" (HERCULANO, 2002, p.2).

Os autores defendem, nesse caminho, a existência de uma relação entre "[...] baixa condição socioeconômica e alta exposição aos riscos ambientais, [...] causando injustiça ambiental para uns e conforto ou segurança ambiental para outros" (LAYRARGUES, 2006, p.19). Assim, torna-se evidente a conexão existente entre a crise ambiental e um contexto amplo envolvendo as dimensões: econômica, política e social as quais fazem parte do modelo civilizatório.

Reafirma-se, assim, que a pressão humana sobre os ecossistemas se dá de forma irregular, isto é, uma pequena minoria dos seres humanos consome grande parte das matériasprimas e energias produzidas, tal que para a garantia desse alto padrão de vida da minoria torna-se necessário lançar mão de altos níveis de recursos materiais, os quais comprometem a sustentabilidade da vida dos demais que não usufruem das benesses de uma vida de riqueza.

O modelo civilizatório estabelece uma relação entre os seres humanos e a natureza que não é inata desses, mas resultado dos vínculos sociais impostos pelo capital. Tal relação é mediada pelo trabalho, que se torna prática alienante quando da dissociação do trabalhador de sua produção, pela venda da força do trabalho, transformando-o em simples mercadoria. A relação mercantil compromete a unicidade entre os seres humanos e a natureza, gerando a 
exploração até o esgotamento tanto da natureza como dos sujeitos enquanto força de trabalho.

Em função disso, Trein (2012) entende que incorporar a dimensão ambiental na educação permite expressar o caráter político, social e histórico que configura a relação que os seres humanos estabelecem com a natureza mediada pelo trabalho. "Ler a realidade de forma crítica nos ajuda a explicitar as relações sociais mercantilizadas e alienantes que perpassam a forma hegemônica de organizar a sociedade" (TREIN, 2012, p.316).

Associada a essas desigualdades, Layrargues (2018) afirma que a educação ambiental reprodutivista, tomada pelo símbolo do antiecologismo, tornou-se dissimulada, como aquela que possui uma intencionalidade persuasiva e domesticadora dos sujeitos, passando a disseminar ideias convenientes ao capital e, ainda, apresentando a problemática ambiental segundo a visão do ambientalismo de mercado. Dessa maneira, passou a oferecer soluções aos desafios ambientais que favorecem ao mercado, apresentando um modelo de sujeito ecológico identificado como o ambientalista moderado, ou seja, aquele que se preocupa em fazer a sua parte na sociedade, disposto, individualmente, a mudar seus hábitos de descarte.

Para o mesmo autor, o direcionamento para essa conscientização ecológica deixa o ser humano preocupado com o destino do lixo doméstico e com o consumo sustentável, mas o mantém alienado acerca da lógica do modo de produção capitalista. Deixa o sujeito atormentado com a "[...] expansão genérica da fronteira agrícola, mas o mantém indiferente à matriz desenvolvimentista estar calcada no robustecimento do setor primário, notoriamente predatório" (LAYRARGUES, 2018, p.36).

Daí que essa educação ambiental reprodutivista acaba por reproduzir os valores e interesses da classe dominante, tratando-os como valores e interesses universais, fazendo, assim, com que a educação ambiental passe a ser controlada, tendo suas implicações políticopedagógicas alinhadas à perspectiva cultural do modelo civilizatório.

De mesma maneira, Loureiro (2015) reflete sobre a necessidade de superação do uso do conhecimento, pois esse está favor da reprodução dos interesses dos grupos dominantes, reconhecendo que os seres humanos vivem em uma sociedade desigual, em que as necessidades podem ser atendidas ou definidas sem a mediação de formas sociais alienadas. Propõe que a ação educativa deva ser direcionada para a construção da igualdade e promoção 
das diversidades, satisfazendo as diferentes necessidades sem opressão, discriminação e reprodução da dominação e dos mecanismos de expropriação.

Ainda para o autor, o conhecimento, ao ser crítico, desafia o ser humano a pensar sobre o ato de conhecer como uma atitude intencional, politicamente posicionada e prática, voltada, por fim, para a transformação social. Nessa perspectiva crítica, não cabe nenhum tipo de messianismo ${ }^{6}$, até porque tal postura seria a negação direta de um posicionamento teórico que coloca a história como movimento materialmente determinado e contraditório.

Reafirma-se que a educação ambiental, nas condições apresentadas, passa por um momento em que está fortemente presente a dicotomia entre a ação de preservar, inserida em uma educação que anuncia boas práticas individuais, e a ação de transformar a realidade, em uma educação que denuncia a insustentabilidade. Está posta a necessidade de superação dessa dicotomia, entre uma educação em defesa dos caminhos alternativos de sustentabilidade e, ao mesmo tempo, outra que trate o combate ao caminho hegemônico da insustentabilidade. Anúncio e denúncia implicam a leitura da realidade e a prática educativa será mais eficaz, não reprodutivista, na medida em que possibilitar aos seres humanos o acesso aos conceitos fundamentais no campo da educação ambiental e, ainda, no momento em que esses mesmos sujeitos passem a ser desafiados a construírem uma compreensão crítica do mundo. Essa prática educativa histórica e cultural, implicada com as condições concretas da realidade, constitui uma educação como caminho em prol das transformações sociais.

Não é possível deixar de refletir, ainda, que os seres humanos estão tomados por fragmentos impostos pelos modelos de produção e consumo vigentes. Fragmentos esses os quais geram minorias culturais diversificadas, tal que nesse momento pares conceituais como universal e fragmento, identidade e diferença, são postos em irreconciliável oposição.

Nessa esteira, torna-se premente que os seres humanos envolvidos na relação educativa consigam identificar e discernir as semelhanças e diferenças presentes no contexto vivido. Nessas condições, o diálogo em Paulo Freire, a partir de sua dimensão ontológica, permite que a partilha entre os sujeitos ganhe centralidade, redefinindo o quadro do poder entre os envolvidos.

\footnotetext{
${ }^{6}$ Para Loureiro (2015) pensar em termos messiânicos seria pensar em termos de salvação, o que impõe defender um mundo tido como perfeito. Não se faz possível confundir o reconhecimento da necessidade de superação de relações sociais objetivadas com a afirmação de uma vida ideal fora da produção social da existência e definida por algum tipo de "iluminado".
}

Periódico Horizontes - USF - Itatiba, SP - Brasil - e020013 
Associado ao diálogo, o reconhecimento da alteridade, da diferença, em Enrique Dussel, é condição constituinte do próprio Eu e do Outro. Inserido nesse contexto, a próxima discussão possui por objetivo apresentar uma reflexão sobre as categorias alteridade e diálogo.

\section{Alteridade e diálogo}

A alteridade é uma categoria fundamental no contexto dusseliano tal que se caracteriza como a "[...] "passagem diacrônica, desde o ouvir a palavra do outro até a adequada interpretação" (DUSSEL, 1986, p.208) do mesmo, de acordo com uma ética pressuposta no ser humano. Dussel afirma-se no exercício do ouvir o Outro, pelo compromisso existencial.

Para o autor, é pelo compromisso existencial, pela práxis libertadora, por um tornar próprio o mundo do Outro que é possível alcançar a interpretação, a conceitualização e a verificação de sua revelação. Nesse momento, em que se caminha em direção a libertação do Outro é que se alcança a própria.

Assim, a história da libertação humana se faz a partir de resultados relativos, nunca finais de tal maneira que para Dussel o caminho é ouvir a voz do pobre, a voz do povo, comprometendo-se com a "[...] humildade e mansidão na aprendizagem pedagógica do caminho de que a palavra do outro, como mestra, vai traçando cada dia" (DUSSEL, 1986, p.209).

Diálogo com os iguais e diferentes, no qual se permite ouvir o Outro, com alteridade é pressuposto fundante na obra freiriana. Pela relação dialógica, a subjetividade se converte em subjetividade humana, no que estabelece a importância ao Outro, diálogo não mais fundamentado na razão pura, mas na possibilidade de ouvir o sujeito. Um diálogo associado à realidade, ao tempo histórico, em prol da responsabilidade social.

Nessa esteira, a proposta freiriana assume uma politicidade epistêmica, ao atribuir um ressignificado aos seres humanos envolvidos na relação educativa, no momento em que o educador em partilha ${ }^{7}$ com o educando promovem a aceitação da condição de ser educando, para aprender pela experiência com os outros.

\footnotetext{
7 No pensamento freiriano, a relação humana autêntica, como relação de sujeitos críticos, expressa-se como relação horizontal. Daí que, a opção de dialogar na diferença, por uma relação dialeticamente contraditória, está centrada na atitude de (com) partilhar.
}

Periódico Horizontes - USF - Itatiba, SP - Brasil - e020013 
O aprender para Freire (2004) remete ao direito de dizer a palavra e quando o ser humano o faz é no sentido de que o ato de dizer a palavra verdadeira seja o de transformar o mundo, imbricado a ação e a reflexão. O pronunciar e modificar o mundo constitui-se como direito de todos os seres humanos, não como privilégio de alguns, de tal maneira que ninguém deve dizer a palavra verdadeira sozinha ou dizer para os outros, mas pronunciá-la na relação de partilha com os outros.

Essa é a razão que remete a impossibilidade do diálogo entre os que desejam a pronúncia da palavra verdadeira e os que não a querem ou, de outra maneira, "[...] entre os que negam aos demais o direito de dizer a sua palavra e os que se acham negados deste direito" (FREIRE, 2004, p.79).

Ao pronunciar o mundo, pela palavra verdadeira, os seres humanos transformam e humanizam esse mesmo mundo e o diálogo passa a constituir-se como caminho para que os sujeitos ganhem significação enquanto seres.

Com esse enfoque, aproximam-se as ideias de Ghiggi (2010) quando o autor argumenta que dentre as categorias elaboradas por Freire, as quais ganham centralidade na revivificação da educação popular, está o diálogo. O mesmo autor, considerando o olhar sobre o contexto da educação popular, advoga que o diálogo toma como ponto de partida o quadro antropológico-cultural, o qual está, intimamente, ligado à vida de quem participa da relação educativa, onde o universo temático, como mundo da cultura dos sujeitos envolvidos, permite a construção do universo vocabular.

Pelo diálogo crítico a realidade não é entendida como abstrata e estática, mas como uma realidade concreta e processual da qual o educando faz parte e torna-se agente das transformações. Essa inserção torna o educando agente de suas ações, de seus interesses, permitindo autorizar-se como aquele que reflete sobre os saberes trabalhados nessa realidade. No momento que o educando exerce esse autorizar-se percebe que está, diretamente, rompendo com a transmissão de conhecimentos.

É pelo diálogo que os desejos e motivos encontrados no trabalhado se tornam aspirações e finalidades humanas. Por isso, o sujeito não está nesse espaço, como algo petrificado, mas está sendo, desenvolvendo-se e em processo. Assim, o diálogo se realiza na dimensão política da educação quando ao partir da situação concreta faz repensar a prática, 
instituindo processos de transformação.

No momento em que Dussel (1977) remete aos níveis concretos da ética latinoamericana, dimensão pedagógica ${ }^{8}$, o faz iniciando pela situação concreta de tal maneira que afirma que o caminho para destruir as "[...] ataduras da liberdade do outro" (DUSSEL, 1977, p.134) é pelo exercício da atitude crítica em que um ser humano chama o Outro a recuperar a sua atitude pessoal. Aproximando ao educador, nessas condições, esse mesmo torna-se um sujeito novo e vive, antecipadamente, a proximidade do face-a-face ${ }^{9}$.

Para Dussel, no contexto educativo o educador deve negar a totalidade fechada, pois essa instaura sempre a novas dominações, mas, de outra maneira, abri-la a alteridade, tal que a passagem da alienação a liberdade se produz pelo caminho da libertação pedagógica.

Nessas condições, problematizar uma educação ambiental transformadora exige partir de uma situação concreta, e pela atitude crítica, em exercício da autoconsciência da alienação, da opressão, reconhecendo, ainda, sofrer a dominação, pensar e agir sobre essa opressão e sobre essa libertação. $\mathrm{O}$ ato de pensar, finalmente, remete a construir um caminhar em que os seres humanos se movimentem dialeticamente em direção a um novo projeto, sempre conduzidos pela palavra do Outro. Com o objetivo de refletir sobre a construção desse novo projeto, a próxima discussão visa apresentar um estudo sobre o respeito à vida e a possibilidade de construção desse novo projeto.

\section{0 respeito à vida e o movimento dialético}

O respeito à vida das classes desfavorecidas, torna necessário pensar em mudanças radicais as quais fundamentem a construção de outro modelo societário a fim de eliminar os mecanismos responsáveis pelas desigualdades e injustiças, como é o caso da exploração econômica, concentração de renda entre tantos outros fatores que acompanham os processos de apropriação privada dos bens materiais.

\footnotetext{
${ }^{8}$ Ao utilizar a dimensão pedagógica Dussel o faz em um sentido mais amplo, para além da ciência da aprendizagem, mas como a parte da filosofia a qual reflete e estuda sobre as relações, pai-filho, mestre-discípulo, político-cidadão dentre outras inseridas no contexto cultural.

${ }^{9}$ A metafísica do face-a-face no contexto dusseliano representa a exterioridade do mestre e do discípulo, do pai diante do filho, em que a alteridade é constitutiva originária e essencial ao mundo da totalidade e, dessa maneira, "[...] 'o Outro' é prévio à invenção a partir de 'o Mesmo'" (DUSSEL, 1977, p.131, grifo do autor).
}

Periódico Horizontes - USF - Itatiba, SP - Brasil - e020013 
De mesma maneira, a preocupação com a vida também está presente na obra de Dussel, tal que para o autor se há uma história do mundo existe, também, uma história da natureza e essa para a modernidade europeia, juntamente, com o trabalho e o capital foram os constituintes da origem do progresso civilizatório. Como isso, a natureza continua economicamente explorada desde a Revolução Industrial, e também "[...] politicamente interpretada; é hermeneuticamente visualizada desde o centro ou a periferia, desde as diversas classes sociais, desde os sistemas políticos, principalmente, como matéria de um modo de produção numa formação socialmente determinada" (DUSSEL, 1977, p.114-115).

Tendo como alinhamento a expansão colonial, momento em que o poder se encontrava dividido entre a aristocracia e a burguesia, a qual gradativamente se impunha pela força do capital, tem-se claro que a promessa da modernidade era direcionada aos sujeitos da Europa Ocidental, aos representantes dessas duas classes.

A colonização dos novos continentes pelos europeus foi encharcada por essa concepção hierárquica, na qual os povos colonizados foram tratados como se fossem seres inferiores, contribuindo para a estruturação de uma ordem social de desigualdades e injustiças as quais se perpetuam até os dias atuais. Essa situação se propaga de mesma maneira, para o campo ambiental, produzindo a situação de que a crise ambiental assume diferentes dimensões para as distintas classes sociais, afetando, de forma mais drástica, os países, ainda, em desenvolvimento e as classes desfavorecidas, as classes pobres.

De mesma forma, o sofrimento com a preservação da vida também está presente na obra de Freire, no momento em que o autor reflete sobre a importância ao acatamento e ao respeito em relação ao Outro, como princípios fundantes de uma relação. Freire (2014), na obra Pedagogia da indignação, acrescenta que além de reverenciar a vida humana deve-se, também, reverenciar a vida "[...] vegetal e animal, o cuidado com as coisas, o gosto da boniteza, dos sentimentos" (FREIRE, 2014, p.77). Resume, assim, a necessidade de que os seres humanos lutem pelos princípios éticos fundamentais como o respeito à vida humana, aos animais e ao ambiente tal que conclama, a todos, ao desenvolvimento da capacidade de amar o mundo ${ }^{10}$

\footnotetext{
10 Para Andreola (2010), Paulo Freire "[...] relaciona a categoria mundo com: a natureza, cultura, história, existência, consciência, trabalho, ação transformadora, palavra e práxis, conceitos através dos quais ele tenta explicar a relação
}

Periódico Horizontes - USF - Itatiba, SP - Brasil - e020013 
Nessa esteira, Freire reflete que a ecologia ${ }^{11}$ ganha uma importância fundamental e que deve estar presente nas práticas educativas críticas e libertadoras, pois essa remete a ação de problematizar as relações entre os seres vivos entre si e, ainda, desses com o meio. Tal concepção de estudar as relações dos seres com o mundo e no mundo implica em analisar os aspectos sociais, culturais, políticos e econômicos.

A partir dessa perspectiva, compreende-se que a educação ambiental não possa restringir-se como aquela que oculta às contradições da realidade, mas considerando sua dimensão ético-política deve estar a serviço de contribuir para a solução dos problemas gerados pelo modelo civilizatório em curso, no momento em que o sistema capitalista representa uma ameaça a sobrevivência de todos.

Assim, a educação ambiental crítica deve estar a favor de compreender as relações entre consciência e mundo, inserida em um contexto em que a educação represente um processo de "[...] denúncia da realidade perversa como do anúncio da realidade diferente a nascer da transformação da realidade denunciada" (FREIRE, 2014, p.102).

Considerando-se a partir de uma perspectiva dialética, o mundo e a consciência se dão simultaneamente, pois a consciência do mundo constitui a consciência do Eu e dos Outros no mundo, mediatizados por esse. Assim, é na inserção no mundo como seres condicionados ${ }^{12} \mathrm{e}$ não na adaptação que os sujeitos se tornam seres históricos e éticos, com a capacidade de decidir e romper com a realidade, criando processos de transformação no cotidiano.

A compreensão das relações entre objetividade e subjetividade para Freire (1980, 2011, 2014) é dialética, não mecânica, no sentido de constituir o pensar e o atuar na realidade para que se possa transformá-la. Nessas condições, para o autor não é possível aceitar a

dialética: leitura do mundo - leitura da palavra, fundamento de toda a alfabetização e de toda a educação" (ANDREOLA, 2010, p.283). Segundo o mesmo autor, para o ser humano, o mundo significa o contexto de sua existência, transformando esse contexto por sua ação.

11 Mesmo que Freire utilize o conceito ecologia, conforme Delizoicov e Delizoicov (2014), a proposta freiriana está alinhada a um estilo de pensamento crítico-transformador em que a concepção de meio ambiente diz respeito a um dado lugar em que os elementos naturais e sociais constituem relações e estão em interação. Tais relações implicam em processos culturais, sociais e históricos de transformação do meio. Por outro lado, segundo os mesmos autores, o estilo de pensamento ecológico é o estudo da natureza, da fauna e da flora, a natureza e os elementos que a cercam.

${ }^{12}$ Freire assume sua opção ao termo condicionado, por crer que ao sujeito imerso em uma situação de opressão lhe será exigida a ação, desde que possuidor da capacidade de reflexão e tomada de consciência. A proposta freiriana não está alinhada a um ser determinado, pois, como tal, esse não vislumbra alternativas de transformação social, econômica e, ainda, política. 
subjetividade de maneira idealista, em que a força da consciência seria condição para modificar o mundo, nem tampouco, do ponto de vista mecanicista em que a subjetividade representa o reflexo das condições materiais, tal que ao transformar a objetividade se modificaria a subjetividade.

Dussel $(1974,1977)$, de mesma maneira, defende um movimento para além do mecanicismo e do idealismo, no momento em que faz uma crítica a filosofia latino-americana a qual deveria estar centrada na possibilidade de pensar o movimento dialético de libertação, em como libertar o ser humano em todos os níveis culturais, ou seja, libertar seu ser negado.

Para o autor, o método dialético engloba os momentos: negativo ${ }^{13}$ e positivo ${ }^{14}$, em uma unidade totalizadora e sempre intotalizada, em um movimento que tende à exterioridade sem abarcá-la. Assim, o método é um momento da realidade dialética em constante processo de mediação. A mediação implica um compromisso existencial, pela práxis libertadora, por um tornar próprio o mundo do Outro, instante em que é possível alcançar a interpretação, a conceitualização e a verificação de sua revelação.

Nessa etapa de mediação, Dussel (1977) determina como momento analético do método dialético aquele em que o ser humano caminha em direção a libertação do Outro. Na analética a partir da aceitação ética da interpretação do oprimido, mediada pela práxis, os seres humanos constituem a condição de possibilidade de compreensão e de esclarecimento, fruto de terem ascendido à exterioridade, "[...] único âmbito adequado para o exercício da consciência crítica" (DUSSEL, 1977, p.164).

Freire e Dussel assumem a importância da objetividade e da subjetividade humana na construção de um mundo socioculturalmente estruturado. Há uma convergência dos autores em estabelecer a conscientização como princípio metodológico tal que o método passa a ter por finalidade a transformação da realidade estabelecida, remetendo aos seres humanos envolvidos na relação à responsabilidade de se tornarem seres da práxis, na procura de transformar o mundo com ação e reflexão.

\footnotetext{
${ }^{13} \mathrm{O}$ momento dialético negativo implica trabalhar a categoria totalidade em que se estabelece a dialética do mesmo, pois se trata de uma categoria unidimensional, única, a qual define a partir do sujeito a identidade e a diferença, tornado-se o fim do discurso, e impossibilitando o diálogo com a alteridade.

${ }^{14} \mathrm{O}$ momento dialético positivo implica, semanticamente, o Outro. A categoria própria do momento positivo é a exterioridade tal que o ponto de partida do discurso passa a ser a exterioridade do Outro e seu princípio é a distinção, a separação, e não mais a identidade, possibilitando o diálogo com alteridade.
} 
Freire (2011) problematiza que somente os seres humanos que refletem sobre suas próprias limitações são capazes de atingir o ato da libertação, desde que a reflexão seja um ato comprometido e aconteça no exercício da ação transformadora da realidade condicionante. "Desta forma, consciência de e ação sobre a realidade são inseparáveis constituintes do ato transformador pelo qual homens e mulheres se fazem seres de relação" (FREIRE, 2011, p.108).

A partir desses pressupostos, não se admite um sujeito isolado, que explore o conhecimento mecanicamente, mas sim um sujeito inserido no contexto, no qual o testemunho seja agente para a tomada de consciência. Decorre daí a responsabilidade do sujeito em relação a um testemunho coerente entre ação e reflexão.

É na partilha, que as determinantes históricas tornam-se percebidas, tal que os seres humanos envolvidos e envolvendo as situações-limites passam a instaurar respostas autênticas aos desafios suscitados. Essa reflexão a respeito das situações-limites, a qual não pode se restringir as individualidades, mas a um coletivo, faz com que a percepção da realidade sociocultural avance na superação tanto do conhecimento abstrato isolado das partes como do conhecimento dedutivo dessa mesma realidade.

Assim, a relação educativa, em favor de uma educação ambiental crítica, deve proporcionar à "[...] desmitologização da realidade" (FREIRE, 2011, p.77), em que o sujeito poderá tomar distância da realidade em que se encontra, para constituir o movimento de inserção crítica nessa mesma, resultando na ação sobre essa realidade constituída. Para além de resultar uma forma de linguagem, o processo busca desvelar as relações dos seres humanos com e no mundo, como modo de ação política, pela consciência de si.

A problematização das situações-limites promove o exercício sobre o pensar diferentes existenciais, possibilitando que os sujeitos se aproximem de sua nova construção, singularizando o processo do qual extraem o problema. É pela constituição dessa singularidade que os seres humanos irão se reconhecer como sujeitos históricos, com possibilidade de ação na realidade.

\section{Considerações finais}

Os pressupostos definidos nas obras de Paulo Freire e Enrique Dussel remetem a reflexão sobre a necessidade de valorização da identidade cultural dos seres humanos, 
identidade essa a qual anuncia a leitura de mundo exercida por esses sujeitos, não raro, subsumida aos modos de produção e consumo impostos pelo modelo civilizatório.

A discussão elaborada no texto, com o foco voltado ao campo da educação ambiental, enfatiza a necessidade de respeito e entendimento diante dos saberes dos sujeitos, tal que essa educação crítica e popular assume seu papel no momento em que marcha na direção da constituição de uma nova realidade e, ao mesmo tempo, denuncia as estruturas desumanizantes. Para que isso aconteça, a prática educativa deve partir da realidade dos seres humanos, mantendo a constante dialetização entre objetividade e subjetividade.

De maneira resumida, refletiu-se a respeito das seguintes ideias força:

- O diálogo - cuja exigência é a escuta de uma prática, de tal maneira que a relação dialógica priorize a vocação ontológica do ser humano, ou seja, a vocação de ser sujeito, promovendo, a compreensão do contexto e dos saberes dos envolvidos na relação;

- A alteridade - da qual a premissa é a necessidade de ouvir o Outro, pois no diálogo deve-se promover ao sujeito o deixar tomar-se pelas razões do Outro, antes mesmo de elaborar a contraposição de ideias, ou seja, o deixar algo em si que foi dito pelo Outro, o exercício da alteridade; e

- A dialética - da qual se assume a importância da história, bem como, do papel da objetividade e da subjetividade humana na construção de um mundo socioculturalmente estruturado, fundamentado nas categorias totalidade e exterioridade.

Acredita-se que o exercício das relações dialógicas, com alteridade, associadas ao método dialético permita o enfrentamento dessa visão dualista de mundo, em que de um lado está a ação de preservar, inserida em uma educação que anuncia boas práticas individuais, e, de outro, a ação de transformar a realidade, presente em uma educação que denuncia a insustentabilidade.

Nessas condições, ainda nesse exercício, torna-se possível perceber a crise ambiental a partir de sua conexão com as condições concretas de uma produção histórica própria, em que a busca desenfreada pela produção ocasionou a falência da unicidade orgânica entre a natureza e os seres humanos. Daí que esses últimos ao não se perceberem parte da natureza, passaram a vê-la como fonte de matéria-prima a ser explorada na expansão do capital, agravando, com isso, a crise socioambiental. 
Por fim, a partir dos pressupostos aqui explicitados, reafirma-se que as obras de Paulo Freire e Enrique Dussel, aproximadas ao campo da educação ambiental crítica, representam marcos conceituais capazes de oferecer sustentação à formação dos seres humanos, formação essa imbricada a transformação social, tal que a apreensão das determinantes históricas seja o foco dessa formação.

\section{Referências}

ANDREOLA, B. Mundo. In: STRECK, D.; REDIM, E.; ZITKOSKI, J.J. (Orgs.). Dicionário Paulo Freire. 2. ed. Belo Horizonte: Autêntica, p.282-283, 2010.

DELIZOICOV, D.; DELIZOICOV, N. C. Educação ambiental na escola. In: LOUREIRO, C.F.B.; TORRES, J.R. (Orgs.). Educação ambiental: dialogando com Paulo Freire. São Paulo: Cortez, p.81-115, 2014.

DUSSEL, E. Método para uma filosofia da libertação. São Paulo: Loyola, 1974.

DUSSEL, E. Para uma ética da libertação latino-americana: acesso ao ponto de partida. São Paulo: Loyola, v.1, 1977.

DUSSEL, E. Método para uma filosofia da libertação: superação analética da dialética hegeliana. São Paulo: Loyola, 1986.

FREIRE, P. Conscientização: teoria e prática da libertação: uma introdução ao pensamento de Paulo Freire. 3. ed. São Paulo: Cortez e Moraes, 1980.

FREIRE, P. Pedagogia da esperança: um reencontro com a pedagogia do oprimido. 9.ed. Rio de Janeiro: Paz e Terra, 2002.

FREIRE, P. Pedagogia do oprimido. 38. ed. São Paulo: Paz e Terra, 2004.

FREIRE, P. Ação cultural para a liberdade e outros escritos. 14. ed. Rio de Janeiro: Paz e Terra, 2011.

FREIRE, P. Pedagogia da indignação. São Paulo: Paz e Terra, 2014.

GHIGGI, G. Paulo Freire e a revivificação da educação popular. Educação, Porto Alegre, v.33, n.2, p.111-118, maio/ago. 2010.

HERCULANO, S. Riscos e desigualdades sociais: a temática da justiça ambiental e sua construção no Brasil. In: ENCONTRO DA ANPPAS, 1., 2002. Anais [...]. Indaiatuba: ANPPAS, p.1-15, 2002. 
LAYRARGUES, P.P. Para que a Educação Ambiental encontre a educação. In: LOUREIRO, C. F. B. (Org). Trajetória e fundamentos da educação ambiental. 2. ed. São Paulo Cortez, p.11-19, 2006.

LAYRARGUES, P.P. Subserviência ao capital: educação ambiental sob o signo do antiecologismo. Pesquisa em Educação Ambiental, São Paulo, v.13, n.1, p.28-47, 2018.

LOUREIRO, C. F. B. Trajetória e fundamentos da educação ambiental. 2.ed. São Paulo Cortez, 2006.

LOUREIRO, C. F. B. Educação ambiental e epistemologia crítica. Revista Eletrônica do Mestrado em Educação Ambiental. Rio Grande, v.32 n.2, p.159-176, jul./dez., 2015.

TREIN, E.S. Educação ambiental crítica: crítica de que? Revista Contemporânea de Educação. Rio de Janeiro, v.7, n.14, p.304-318, ago./dez. 2012.

Recebido em abril de 2019.

Aprovado em dezembro de 2019. 